\title{
Article
}

\section{Oral health should be considered when working with adults with intellectual disabilities, and larger, higher-quality studies in this area are needed}

Hill, James Edward, Doherty, Alison Jayne and Firestone, Jayne Available at https://clok.uclan.ac.uk/30474/

Hill, James Edward orcid iconORCID: 0000-0003-1430-6927, Doherty, Alison Jayne orcid iconORCID: 0000-0003-3593-8069 and Firestone, Jayne (2019) Oral health should be considered when working with adults with intellectual disabilities, and larger, higher-quality studies in this area are needed.

Evidence Based Nursing . ISSN 1367-6539

It is advisable to refer to the publisher's version if you intend to cite from the work. http://dx.doi.org/10.1136/ebnurs-2019-103171

For more information about UCLan's research in this area go to http://www.uclan.ac.uk/researchgroups/ and search for <name of research Group>.

For information about Research generally at UCLan please go to http://www.uclan.ac.uk/research/

All outputs in CLoK are protected by Intellectual Property Rights law, including Copyright law. Copyright, IPR and Moral Rights for the works on this site are retained by the individual authors and/or other copyright owners. Terms and conditions for use of this material are defined in the policies page. 
Category: Nursing issues

Study type: Quantitative study - other

Author's declarative title: Oral health should be considered when working with adults with intellectual disabilities, and larger, higher-quality studies in this area are needed.

Commentary on: Ward, LM., Cooper, SA., Hughes-McCormack, L., et al. Oral health of adults with intellectual disabilities: a systematic review. Journal of Intellectual Disability Research. May 2019. https://doi.org/10.1111/jir.12632

\section{Commentary}

Implications for practice and research

- Larger, higher-quality studies are needed to investigate the oral health needs of adults with intellectual disabilities.

- Specific training in oral hygiene care and oral disease management should be given when working with adults with intellectual disabilities.

\section{Context}

Poor oral health can have a harmful influence on an individual's self-esteem, selfimage, social interaction, stress, mood and can cause other health problems (1). In a previous systematic review, it was highlighted that adults with intellectual disabilities were more likely to experience poor oral health compared to the general public (2). Since this publication there has been a wide range of international research and policy development looking at specifically improving oral health for adults with intellectual disabilities (3). This systematic review carried out by Ward and colleagues examined if adults with intellectual disabilities still experienced poor oral health, and if so, to what extent (4). The secondary objective was to identify what were the most common methods used to examine oral health within the relevant literature.

\section{Methods}

This PROSPERO registered systematic review searched multiple databases (EMBASE, MEDLINE, PsycINFO, WoS) from 2008 to July 2018. Only English language peer reviewed observational studies which examined oral health status of adults (aged 18+) with intellectual disabilities living in the community were included. Screening and data extraction were carried out by one reviewer with $10 \%$ of screened studies and quality assessment (Critical Appraisal Skills Programme) being verified by a second reviewer. 


\section{Findings}

The findings from the review highlight that adults with an intellectual disability still experience poor oral health. Poor gingival health was frequently reported, with gingival signs being reported in $23.3 \%$ to $88.1 \%$ of adults with an intellectual disability. The more severe form of periodontal health of periodontitis were identified in $22.5 \%$ to $69.2 \%$. In addition to poor periodontal health there was a "high prevalence" of untreated dental decay with the prevalence of decayed teeth ranging from $26 \%$ to $52.9 \%$. The most commonly used method to identify these issues was clinical oral examination.

\section{Commentary}

This review adds to findings from previous systematic reviews which have identified a high prevalence of poor oral health in adults with an intellectual disability (2). The methodology was clearly and concisely reported, however there are three main fundamental issues which should be considered when interpreting the results of this review.

The first issue is that studies used heterogeneous samples of participants. That is, these participants varied in age, gender, type of disability and country of origin. This wide variation makes it difficult to synthesize the findings from the included studies, as they all looked at a different population (5). The second issue is that a majority of the included studies, as acknowledged by the authors, may not be representative of the general population of adults with an intellectual disability: some studies used dental service users (only) or Special Olympics participants (only). Based on these issues it is questionable how these findings can be generalized to the general population of adults with an intellectual disability.

The third issue relates to the review's use of comparisons. For example, inappropriate comparisons were made between different definitions and measures used in oral health. In addition, there were few identified studies using a control group to compare the oral health of people with intellectual disabilities to members of the general public.

Due to the first two issues and other aspects of the included studies, the primary evidence was identified to be of low quality. Although some of these limitations were addressed and contextualized within the discussion section, extreme caution should be taken when interpreting the results. Despite the poor-quality primary evidence and lack of appropriate comparison, specific training in oral hygiene care and oral disease management should be given when working with adults with intellectual disabilities. Furthermore, the review's findings do highlight the need for further robust research (including prevalence and incidence studies, controlled trials, and qualitative studies) to explore oral health needs and issues for individuals with intellectual disabilities. 


\section{References}

1. Rozier RG, Pahel BT. Patient- and population-reported outcomes in public health dentistry: oral health-related quality of life. Dent Clin North Am. 2008;52(2):345-65, vivii.

2. Anders PL, Davis EL. Oral health of patients with intellectual disabilities: a systematic review. Spec Care Dentist. 2010;30(3):110-7.

3. Waldron C, Nunn J, Mac Giolla Phadraig C, Comiskey C, Guerin S, van Harten MT, et al. Oral hygiene interventions for people with intellectual disabilities. Cochrane Database Syst Rev. 2019;5:CD012628.

4. Ward LM, Cooper SA, Hughes-McCormack L, Macpherson L, Kinnear D. Oral health of adults with intellectual disabilities: a systematic review. J Intellect Disabil Res. 2019.

5. Higgins JG, S. Cochrane Handbook for Systematic Reviews of Interventions Version 5.1.0 [updated March 2011]: The Cochrane Collaboration; 2011.

\section{Commentator details}

Name: James Edward Hill

Affiliation: University of Central Lancashire

Correspondence address:

University of Central Lancashire,

Preston, Lancashire

PR1 2HE

Email: Jehill1@uclan.ac.uk

\section{Competing interests}

I have no conflicts of interest with any aspect of this publication 